\title{
MAX AUB O EL PODER TESTIMONIAL DE LA FICCIÓN
}

\author{
JAVIER SÁNCHEZ ZAPATERO ${ }^{1}$ \\ Universidad de Salamanca
}

\begin{abstract}
Resumen
Como víctima y superviviente de la violencia y la intolerancia, Max Aub fue consciente de la obligación moral que tenía de dar cuenta de todo lo que había vivido en el desgraciado periplo que, entre 1936 y 1942, le hizo ser testigo de las guerras española y mundial, de la brutalidad de los campos de concentración franceses y de la soledad del exilio al que partió en 1942. Con esa autoimposición como punto de partida, este trabajo intenta analizar la obra de Aub a partir de su condición testimonial, al tiempo que indaga en las concepciones literarias del autor, basadas, grosso modo, en la paradoja de confiar más en la ficción como medio de transmisión de su pasado que en su propia memoria.
\end{abstract}

Palabras clave: Max Aub, Ficción, Autobiografía, Testimonio, Compromiso.

\begin{abstract}
As victim and survivor of the violence, Max Aub wanted to narrate his unfortunate experience on 1930's and 1940's: Spanish Civil War, World War II, French concentration camps and exile. In this way, his literature arose as consequence of a moral obligation to testify. This article tries to analyze Aub's books from two differents points of view: the study of the historical condition of Aub's literature and the study of the literary conceptions of Aub, because they were based on the paradox of prefering the fiction to the memory in order to narrate the past experience.
\end{abstract}

Key Words: Max Aub, Fiction, Autobiography, Testimony, Commitment.

A principios de 1939, ante la inminencia de la victoria franquista en la Guerra Civil, Max Aub -cuyo compromiso con el gobierno republicano durante la contienda había quedado fuera de toda duda-cruzó la frontera y se instaló en París. Allí viviría unos meses, hasta que una denuncia falsa por la que se le acusaba de comunista provocó su arresto por parte de las autoridades francesas y, con ello, el inicio de una peregrinación por diversos espacios carcelarios y concentracionarios que se prolongaría hasta 1942, cuando pudo huir y embarcar hacia México, donde se instalaría definitivamente. Derrotado, excluido del proyecto nacional, exiliado y superviviente de los campos de

1 Universidad de Salamanca. Correo-e: zapa@usal.es. Recibido: 15-11-2009; segunda versión: 10-032010. 
concentración, Max Aub (1998: 23) aseguraba "no tener derecho a callar"2 lo vivido durante su desgraciada peripecia vital. La famosa sentencia fue ejecutada por el autor desde el momento en que constató que, en su condición de víctima de la intolerancia, su figura formaba parte de la "memoria impedida" y la "memoria manipulada" que surgían, según Paul Ricoeur (2004), como consecuencia del "control de la memoria" al que sometieron a sus sociedades diversos regímenes totalitarios y al que, evidentemente, no fue ajeno el franquismo. El escritor fue consciente de que ni su nombre ni su obra podrían ser recordados correctamente en la España de la dictadura, dominada por un aparato propagandístico empeñado en presentar a los exiliados como "defensores del monstruo, acusados de que han robado el oro de España y complotan en la ONU" (Cuesta, 2008: 148) y en borrar todas las huellas que evocasen el legado republicano.

En su lucha contra la deformación histórica del franquismo y a favor del legado republicano y de todos los quelucharon por su mantenimiento, fuela literatura el método más eficaz de todos los empleados por el autor. No en vano, Sebastián Faber (2003: 11) ha llegado a interpretar la "extraordinaria fecundidad aubiana" como "reacción particular al trauma del exilio, una respuesta a los conflictos y a las obligaciones que el destierro conlleva para el escritor, sobre todo con respecto a la lealtad y la memoria". Para Caudet (2000: 26), la prolijidad de su producción ha de entenderse como forma de conseguir "autoestima, justificación [y] razón de ser", elementos especialmente importantes para quien se ve despojado de sus asideros vitales en el exilio. El propio Aub, de hecho, señalaba en 1971, en un cuestionario formulado por Fernando Palacios Álvarez, que "resolvió su experiencia del exilio escribiendo" (FMA, Caja 19, 6) ${ }^{3}$. La abundancia de su obra puede entenderse así como una respuesta a la actuación de quienes intentaron borrar e inventar a su antojo partes de la historia, sobre todo si se tiene en cuenta que en ella bulle una constante preocupación por reflejar la realidad.

Según el autor, las novelas "son testimonios" (FMA, Caja 13, 19, 26) equiparables al discurso historicista y la labor de los escritores ha de ser análoga a "la de ciertos clérigos o amanuenses en los albores de las nacionalidades: dar cuenta de los sucesos y recoger cantares de gesta" (Aub, 2002: 49). Para Aub, los errores en que pueden incurrir la memoria personal o las indicaciones de los testigos son susceptibles también de afectar a las fuentes documentales con que trabajan los historiadores. "El novelista -afirmaba el autor en 1968, en una entrevista inédita conservada en la Fundación Max Aub- está tan cerca de la historia y de la verdad histórica (...) como todo historiador"4 (FMA,

2 "Habiendo tanto que decir, tanto que, por mucho que hagamos, siempre quedarán casos que poner en relieve, ¿para qué inventar? Creo que no tengo derecho a callar lo que vi para escribir lo que imagino" (Aub, 1998: 123).

3 Para elaborar este artículo se han consultado los fondos de la Fundación Max Aub, institución que, sita en Segorbe, se encarga de custodiar todo el legado documental del autor, formado por cartas, manuscritos, anotaciones y entrevistas personales Para referirse a los documentos consultados se ha utilizado el mismo modelo de citación que, basado en el sistema numérico, emplean los trabajadores de la fundación para archivarlos.

$4 \mathrm{Al}$ hacer hincapié en las tenues barreras que separan literatura e historia, el pensamiento estético de Aub se convierte en un claro precedente de las teorías de Hayden White, para quien las interacciones entre ambas disciplinas han llevado, por un lado, a los historiadores a construir sus discursos como si 
Caja 13, 19, 26). Muy crítico con la actitud reverencial con la que las fuentes escritas eran interpretadas -contraria al escepticismo que los historiadores acostumbraban a mostrar ante las opiniones e impresiones personales-, Aub era consciente de que los documentos, al igual que las personas, podían mentir:

Este intento de los historiadores que se quieren basar exclusivamente en los documentos y hacer que ellos sean fehacientes, es un absurdo, porque los documentos mienten como los hombres (FMA, Caja 13, 19, 26).

Lo sabía por la experiencia de su propia vida, brutalmente condicionada por un documento que mentía. Recuérdese que el arresto que motivó su ingreso en cárceles y campos de concentración francesas, y que meses después le obligó a partir rumbo al exilio mexicano ante el peligro que su libertad y su seguridad pudieran correr en la Francia ocupada, vino provocado por una denuncia falsa en la que, entre otras inexactitudes, se decía que era alemán, judío y comunista ${ }^{5}$. Las autoridades francesas, que habían investigado al autor desde su trabajo, en tiempos de la Guerra Civil, en la Embajada española, y sabían de sus contactos con destacados simpatizantes comunistas como André Malraux, recibieron, en el paranoico clima bélico en que vivía inmerso Francia en el año 1940 -en el que todo aquel que se salía de lo convencional era acusado de disidente-, una nota del embajador del gobierno franquista en el país galo, José Félix de Lequerica. El diplomático, haciéndose eco de una falsa y denuncia anónima, instaba al gobierno francés a que tomase medidas contra "este comunista notorio de actividades peligrosas" (Malgat, 2007: 90).

Para Gerard Malgat (2007: 103), el impacto de la falsa denuncia en Aub no sólo está relacionado con la lógica decepción que surge al comprobar cómo toda una vida puede ser condicionada por una mentira gratuita, sino también con la constatación de que los límites de conceptos como realidad y ficción son tan difusos como volubles, algo que influirá, y mucho, en su concepción artística:

La identidad ficticia creada al hilo de los informes represivos (...) dejará huellas en lo más profundo de su ser y una pesada carga de heridas interiores frente a las muchas arbitrariedades y persecuciones sin motivo. Ello influirá también en sus concepciones filosóficas y las relaciones - paradójicas- que establecerá su obra literaria con la verdad de la ficción y lo falso de la realidad, en particular de la realidad producida por los servicios represivos de un Estado que se involucra en la colaboración con el agresor nazi.

El propio autor, en una carta enviada al presidente mexicano en 1951 recogida en la compilación de ensayos Hablo como hombre, reflexionó sobre esa idea:

Estoy fichado y (...) esto es lo que cuenta, lo que vale. Que lo que diga la ficha sea verdad o no, eso no importa, ni entra en juego. Es decir, que yo, mi persona, lo que pienso, lo que siento, no es la verdad. La verdad es lo que está escrito. (...) Yo, Max Aub, no existo: el que vive es un peligroso comunista que un soplón denunció un día, supongo que por justificar su suelo. (...)

de un relato se tratase y, por otro, a los novelistas a convertirse en intérpretes válidos de la realidad histórica.

5 “Max Aub. Nacionalidad alemana. Nacionalizado español durante la guerra civil. Actividades: comunista y revolucionario de acción. Se cuenta su presencia en Francia. Llamar la atención del embajador sobre el mismo como sujeto peligroso. Decir a los consuls [sic] que no le den visado y le recojan el pasaporte si se presenta. Decirles à [sic] Madrid" (Malgat, 2007 89-90). Sobre la hoja manuscrita que contenía la denuncia, alguien -probablemente algún funcionario de la Embajada- escribió la palabra "hebreo". 
Pero yo no soy comunista ni 'comecomunista', soy un liberal, un socialista liberal (...), que fue falsamente acusado de ser comunista (Aub, 2002: 113-114).

También fue consciente de la desconfianza que se había de mantener ante determinadas reconstrucciones de la historia por la evolución de su país, dirigido por un gobierno ilegal, sólo respaldado por la fuerza de las armas, y, sin embargo, legitimado por la comunidad internacional a través de su ingreso en diversos organismos y del mantenimiento de relaciones exteriores.

El autor se mostró muy crítico con la interpretación histórica efectuada por los poderes franquistas, basada en la deformación y en las falsedades. "La vida española de hoy está construida en la mierda de la mentira" (Aub, 2003: 433), llegó a decir cuando regresó a España en 1969, contrariado por el hecho de que una de las consecuencias de esa mentira fuera precisamente su desaparición -y la de todos los literatos que compartieron con él la amarga aventura del exilio- de los catálogos editoriales, las librerías, los medios de comunicación, las universidades y los centros de enseñanza y reflexión cultural españoles. Como ha señalado Manuel Aznar, “para quienes padecieron el régimen educativo [franquista] nada más normal que ignorar en literatura o en historia un siglo XX que no se explicaba o se explicaba poco y mal" (Aznar, 2003: 29). Así lo comprobó el propio autor, que se lamentaba de que durante la dictadura la gran mayoría de españoles "jamás oyeron el santo de [su] apellido" (Aub, 2003: 127). La importancia de este vacío cognoscitivo residía, fundamentalmente, en que demostraba la susceptibilidad de manipulación de la memoria colectiva e histórica de las sociedades, así detectada por el propio autor:

Un testamento puede servir precisamente para ocultar la fortuna de un señor y porque es un documento del siglo XVI, los historiadores aseguran feroces: la verdad ésta, y no lo que cuenta fulanito de tal en una novela de la misma época. Pero, ¿por qué? ¡Si los documentos están hechos para engañar a la gente! En eso no hay duda alguna de que los hechos mismos que están sucediendo actualmente en el mundo, si pasaron siglos o uno cayera de la luna y se basara en los documentos, por ejemplo, de la invasión de Checoslovaquia (...), y leyera los documentos soviéticos exclusivamente, pues, quedaría convencido, diría: son documentos, aquí están. ¿Quién se lo iba a negar? Y, sin embargo, sería falso (FMA, Caja 13, 19, 26).

Es decir, según Max Aub, los textos históricos $-\mathrm{y}$, en general, todos los referenciales- pueden aprovechar la actitud del receptor y el siempre subyacente e implícito pacto de veracidad que se establece ante su lectura para manipular al lector y hacerle creer como ciertos hechos que jamás sucedieron. En la propia obra del autor se pueden encontrar buenos ejemplos que demuestran que los documentos pueden mentir. Quizá el más representativo y famoso sea Jusep Torres Campalans, la biografía ficticia de un pintor vanguardista nacido de la imaginación de Aub y existente sólo en su cabeza. Publicado en 1958 por la editorial Tezontle, el libro se presentó imitando los títulos de la colección "Le goût de notre temps" de Alberto Skira y, tanto por sus contenidos como por su aspecto formal, como si de una monografía artística se tratase. De este modo, además de reproducir contenidos habituales de textos similares, como los anales, el catálogo del autor o la reproducción de algunas de sus obras ${ }^{6}$, el texto

6 El propio Aub pintó las obras incluidas en el texto, atribuidas, lógicamente, al falso Campalans. 
apareció con las mismas características externas de las clásicas colecciones de arte. Con ello se ponía de manifiesto el interés del autor en que lo mostrado en el texto fuera interpretado como verdadero por los lectores, tal como ha señalado Juan Manuel Bonet (2004: 132-133):

El diseño juega un papel clave: forma parte, por decirlo de alguna manera, de la ficción. De lo que se trata es de parodiar, con intención mixtificadora, una monografía (...) para contribuir a que el lector se crea que está ante el redescubrimiento de un pintor cubista olvidado, casualmente conocido por el autor, que adopta las formas del historiador del arte.

Guiados por lo que sugería el paratexto, fueron muchos los que hicieron una interpretación histórica de la obra, tomando por real y no por ficcional la vida del pintor catalán. No en vano, hubo hasta representantes de la crítica artística del momento que dieron por cierta la existencia de Torres Campalans. De la misma forma, conocidos de Aub como Juan Luis Alborg mostraron su enfado por el autor por no aclararles si el pintor había existido realmente o no ${ }^{7}$ (FMA, Caja 13, 19, 18). Michael Ugarte (1999: 142) ha explicado del siguiente modo el impacto del aparente carácter mimético del texto:

La forma académica en que el biógrafo ordena los documentos llevó a los críticos de arte y a los historiadores de la cultura a evaluar seriamente al pintor. En efecto, el mundo del arte había descubierto un nuevo artista cubista. Intelectuales y artistas en México donde, según el biógrafo, Torres acababa de morir, y hasta en Nueva York, declararon que habían visto sus obras o que habían tenido la suerte de conocerlo.

ParaSoldevila(1999:130), el textoes la“más sonadabroma” delas letrasespañolas. Sin embargo, no se ha de interpretar la obra como un mero juego del autor destinado a confundir a lectores y, especialmente, al mundo del arte. Más allá de su actitud lúdica, Jusep Torres Campalans demuestra la imposibilidad de confiar en los documentos y la forma en la que éstos, a pesar de su rigor y aparente objetividad, pueden incurrir en falsedades y errores. En ese sentido, resulta sumamente esclarecedor plantear la hipótesis de que hubiera sucedido si la obra de Aub hubiera pasado desapercibida, sin comentaristas ni críticos dispuestos a analizarla, y hubiera sido descubierta pasados unos siglos. Probablemente, en semejante situación, quienes hubiesen encontrado el libro de Aub no hubiesen tenido ninguna duda de que Jusep Torres Campalans existió, de que nació en 1886 y de que a mediados del siglo XX permanecía, alejado de la vida pública, retirado en el estado de Chiapas. Al presentarse como una monografía artística, y no como una obra de ficción, hubiera activado un contrato lector basado en la confianza en la referencialidad de su contenido.

Semejantes efectos a esa hipotética lectura futura de Jusep Torres Campalans produciría la de Antología Traducida, compilación de poemas de más decincuenta autores -de diversas culturas, épocas y tradiciones- tan inexistentes como el pintor catalán. Aub es, consecuentemente, autor tanto de las composiciones como del aparato textual que las acompaña. La confusión de los lectores, así como los problemas de recepción, vienen provocados porque, en su labor de antólogo y editor, el escritor mezcló -al

7 Rizando el rizo de esa errónea percepción, incluso hubo quien creyó reconocer en Campalans rasgos de personas reales, como mostró el autor en sus diarios: “La hija de Campalans. La hija del diputado socialista de idéntico apellido quiere hablar conmigo: está convencida de que tomé a su padre como modelo (...) ¡Resulta que el hombre pintaba!" (Aub, 1998: 393). 
igual que hizo en Jusep Torres Campalans, donde aparecen figuras como Alfonso Reyes o André Malraux- elementos de la ficción con elementos reales. Es decir, aludiendo a la teoría de los mundos narrativos de Albaladejo, sus obras muestran un modelo ficcional verosímil presentado bajo la apariencia de mundo verdadero ${ }^{8}$. En el prólogo de Antología Traducida se puede leer, por ejemplo, que el traductor de muchos de los poemas es Juan de la Salle, de quien se dice que "pasó no pocas horas con Jorge Guillén y Pedro Salinas, de quien fue amigo" (Aub, 2004: 56). También Imposible Sinaí ha de ser señalado como muestra del interés del autor en la "poética de lo falso", expuesta en este caso a través de una selección de composiciones atribuidas a participantes en la Guerra de los Seis Días. Versiones y subversiones es otro de los trabajos aubianos merecedores de integrar este grupo.

No fueron estas las únicas obras en la que el autor cuestionó la validez de los documentos textuales como forma de conocer el pasado. Cuando se cumplían catorce años de su exilio mexicano, el autor imaginó su acto de ingreso en la Academia de la Lengua Española y escribió el habitual discurso deentrada a la institución, siguiendo para ello los tópicos retóricos habitualmente empleados en ese tipo de textos. Demostrando su interés por las artes gráficas, Aub se encargó de que el discurso, titulado El teatro español sacado a la luz de las tinieblas de nuestro tiempo, fuese editado imitando la tipografía y el diseño habitual de las publicaciones de la institución junto a la correspondiente réplica, a cargo de otro académico tan imaginario como él, Juan Chabás ${ }^{9}$, quien ya había fallecido en la fecha del supuesto acto de ingreso. La presentación formal del texto constituye, como en el caso de Jusep Torres Campalans, una muestra de la intención del escritor de, en su deseo de legitimar a la literatura como forma de conocimiento, otorgar estatuto de realidad a elementos ficticios, diluyendo así los límites entre ambas entidades, pues, tal y como ha explicado Javier Pérez Bazo (2007: 351), “la edición del opúsculo sirve de soporte real o prueba que el autor desea convincente de su historia ficticia, como si dotándola de realidad física quisiera violentar el curso de la Historia negando lo imposible".

En consecuencia, " para el Max Aub del discurso, la guerra civil nunca existió y, por tanto, ni la muerte, ni el exilio habían azotado España" (Mas i Uso, 2006: 76). En la Academia imaginada por el autor, que, por motivos obvios, no podía ser "real" en

8 Según Albaladejo (1986), un texto puede remitir a tres "modelos de mundo": verdadero, ficcional verosímil y ficcional inverosímil. El primero de ellos sería el referente habitual de los textos historiográficos y periodísticos, mientras que los otros dos se identificarían con la tradicional división aristotélica de los contenidos en miméticos y no miméticos. La novela que intenta recrear el pasado verdadero, histórica en algunos casos y testimonial en otros, tendría un referente -formado por ambientes, personajes, tiempo, tramas, etc.- exclusivamente real, tomado íntegramente de la historia verificable, y se distinguiría de otros textos tanto en su voluntad formal como en su proceso de recepción, puesto que los lectores no esperan de ella el detallado y exacto rigor que sí se exige a la historiografía. En ocasiones, ese mundo verdadero puede convivir en la novela con un referente ficcional verosímil, que, a pesar de no proceder de la realidad, está construido a partir de ella.

9 El discurso atribuido a Juan Chabás reproduce fragmentos de uno de sus trabajos de historia literaria, Literatura española contemporánea (1898-1950). Del mismo modo, el texto con el que Aub se estrenaba como académico utiliza fragmentos del "Proyecto de estructura para un teatro nacional y escuela nacional de baile" presentado ante el gobierno de la II República poco antes de la guerra. 
ninguno de los sentidos, se sentaban Federico García Lorca, Miguel Hernández o Ramón J. Sender junto a Ernesto Giménez Caballero, José María Pemán o Dionisio Ridruejo. Vencedores y vencidos, muertos y vivos, se daban la mano en una sociedad que no había sufrido los horrores de la guerra, que conmemoraba el veinticinco aniversario de la proclamación de la II República y que tenía en Max Aub a uno de sus más destacados dramaturgos, hasta el punto de ser académico y director del Teatro Nacional. Aunque todos los personajes que aparecen en el texto son históricamente reales, muchos de sus rasgos biográficos aparecen alterados, siendo sus vidas ficticiamente alargadas, adquiriendo sus obras una continuación que nunca tuvieron y convirtiéndose en académicos autores que jamás lo fueron -o que, como en el caso de Miguel Delibes, sólo lo serían años tarde-. De ahí que el texto pueda ser tomado como un homenaje a la tradición cultural de un grupo de escritores cuya evolución fue abruptamente alterada por la guerra y por la dictadura. La obra, por lo tanto, no sólo cuestiona la fiabilidad de las fuentes históricas, sino que también y sobre todo se convierte en una forma de luchar contra el olvido y la manipulación efectuada por los poderes franquistas.

El discurso es, consecuentemente, una forma de apelar a la reflexión de los lectores y de buscar en ellos una reacción condenatoria contra la dictadura de Franco gracias a la muestra de lo que pudo ser y no fue. En ese sentido, el texto aubiano no se limita a mostrar lo difuso de los límites entre ficción y realidad, sino que también se convierte en elemento al servicio de la memoria de la España de la II República y de todos los que por defenderla hubieron de salir al exilio ${ }^{10}$.

Es sintomático comprobar cómo, si bien en los ejemplos analizados hasta ahora, Aub mostró un universo ficcional como si de uno referencial y verificable se tratase, en su inacabado proyecto de biografía de Luis Buñuel ${ }^{11}$ tuviera previsto actuar de manera inversa, presentando datos y testimonios reales bajo el título de Buñuel, novela ${ }^{12}$. Para el autor, su trabajo sobre el pintor aragonés iba a ser un "texto entre la historia, la vida

10 A pesar de ser el más conocido, el discurso no es el texto el primero ni el único ejemplo de ucronía que se puede encontrar en la producción aubiana. De hecho, la omisión de la Guerra Civil es también el punto de divergencia histórica a través del que se estructura del relato "De los beneficios de las guerras civiles", en el se imagina cómo hubiera sido la evolución de una familia de no haber existido la guerra. Ya en 1947, el autor había publicado dos artículos -“Aquí no ha pasado nada" y "Gloria borbónica" (Meyer, 2007)- en el periódico mexicano El Nacional en los que otorgaba la voz narrativa a una periodista que se desplazaba a España para cubrir una hipotética restauración borbónica producida años después de la Guerra Civil.

11 Editado y prologado por Federico Álvarez -yerno del escritor-, el libro -o, más bien, la documentación que Aub había ido recopilando para su elaboración- fue publicado póstumamente en 1985 bajo el título de Conversaciones con Buñuel. Seguidas de 45 entrevistas con familiares, amigos y colaboradores del cineasta aragonés. En la Fundación Max Aub se encuentran recogidos varios manuscritos de trabajo que complementan la publicación.

12 Joan Oleza (2005: 23) ha expuesto las relaciones existentes entre Jusep Torres Campalans y el libro sobre Buñuel: "Las semejanzas de los dos libros son múltiples. Se trata de la vida de dos artistas conocidos de Aub -aunque Campalans lo sea de manera supuesta-, de quienes él emprende la tarea de escribir una biografía: la primera, la de Campalans, por la -otra vez supuesta- curiosidad que siente al encontrarse al misterioso personaje en Chiapas y saber que era un pintor cubista importante, la segunda, la de Buñuel, por encargo de una editorial. Sin embargo, también se hace una diferencia importante, que conlleva una semejanza de principio: si, en el caso de Jusep Torres Campalans, Aub ofrece una biografía de un personaje ficticio, en el caso del Buñuel, aun cuando le proponen el trabajo como una biografía y que se trata 
y el arte (...): una novela" (FMA, Caja 14, 8, 7). En el prólogo de la obra advertía Aub (1985: 20) a sus lectores de la necesidad de cuestionar todo su contenido:

Todo cuanto sigue puede ser muy bien una sarta de mentiras o verdades a medias -que viene a dar lo mismo-, pero tengo la esperanza de que el resultado dará cuenta de las suposiciones -propias y ajenas- de por qué fuimos como fuimos. Ahora bien, antes que los lectores tomen cuanto digo por cierto -así haya sido yo autor del suceso-, póngalo, por si acaso, en cuarentena. Todo es diversidad de pareceres y cualquier cosa puede ser otra. Las imágenes engañan tanto como las palabras. Tener algo presente ante los ojos no quiere decir que el fotógrafo, el escritor, el pintor sea capaz de transmitirlo. No depende sólo de él, sino del que ve o lee. Una es la cosa, otra quien la mira y copia, otra quien la ve copiada ¿y así quieren verdad? No hay otro modo, sin embargo.

El método de trabajo que empleó el autor para la composición de obra revela su convencimiento -plenamente posmoderno- en el carácter inaprensible de la realidad. Aub basó su labor de documentación en entrevistas personales, pero jamás dio por veraz una sola fuente sin antes contrastarla. "Cuando dos o tres han coincidido lo di por cierto -manifestaba en una de las múltiples anotaciones encontradas entre los materiales con los que trabajó para elaborar la obra-, un solo testimonio me ha dejado en duda, a menos que fuera reciente" (FMA, Caja 14, 8, 7). Sin embargo, lejos de dar por válidas sin más las declaraciones de que disponía, el autor utilizó las diferentes versiones que de la vida de Buñuel obtuvo para mostrar su caleidoscópica visión de la realidad, pues él mismo explicó que se había dado cuenta "de que no había manera de desentrañar lo sucedido, porque no hay un suceso, sino tantos como testigos auténticos" (FMA, Caja 14, 8, 7).

$\mathrm{Al}$ establecer esta tesis en un texto de intenciones biográficas -y aparentemente referencial, por tanto-, el autor cuestiona la validez de todos los elementos que conforman el proceso del saber histórico y propone, al mismo tiempo, un nuevo modelo cognoscitivo. Tal y como ha expuesto Gabriel Rojo, "si el objeto histórico es inaprensible de manera directa, y los caminos indirectos, como son los documentos y los testimonios, tienen una veracidad dudosa y una validez cuestionable (...), [se ha de entrar] en el terreno de la ficción" (Oleza, 2005: 24). Consecuentemente, la mejor manera de abordar la vida -real- de Luis Buñuel es recurrir al discurso literario ${ }^{13}$, pues, como dijo el propio Aub, él no era más que un "novelista que buscaba la verdad a través de la literatura" (FMA, Caja 14, 8, 6). El autor concebía su función, más que como la de un biógrafo o la de un mero creador, como la de un "reconstructor" encargado de recoger las diferentes versiones que de la vida de Buñuel existían y de cotejarlas con las fuentes documentales para establecer un retrato que fuera tan poliédrico como real. "Lo que

de un personaje que existió y fue su amigo, Aub pretende ofrecerlo como novela. Así, en el primer caso, una ficción que se quiere presentar como 'histórica': en el segundo caso, hechos históricos novelados".

13 Y, paradójicamente y para poner de manifiesto la continua difusión de los límites entre realidad y ficción, la mejor manera de abordar la vida -ficticia- de Jusep Torres Campalans es recurrir al discurso histórico. 
quiero es intentar un retrato en movimiento" (Aub, 1985: 33), confesaba en el proyecto de prólogo que escribió para Buñuel, novela al explicar sus intenciones ${ }^{14}$.

Aub complementaba la desconfianza en la funcionalidad de los relatos convencionales para reflejar la realidad con una escéptica mirada sobre la memoria, que, para él, era "de lo más traicionero que existe en el mundo" (FMA, Caja 12, 31, 8). Así lo pudo comprobar, cuando, documentándose para escribir el pasaje de su novela La calle de Valverde en el que se recrea lo sucedido en la "Sanjuanada" -el fracasado proyecto de Golpe de Estado que algunos militares idearon en 1926 para derrocar a Primo de Rivera-, descubrió cómo "los mismos militares que habían tomado parte en el intento de sublevación (...) se equivocaban, no de un año, de dos años, [sino] de cosas que habían pasado aquí y no allá" (FMA, Caja 13, 19,10) o cuando dos testigos a los que preguntó por las circunstancias de la salida de España de Negrín durante la guerra le dieron versiones contradictorias (FMA, Caja 13, 19, 10).

El problema de la verdad inaccesible estuvo presente en la vida del autor desde sus inicios. No en vano, ya en la infancia se sintió Aub (apud Malgat, 2007: 32) desconcertado por no saber cuáles eran las razones exactas que habían provocado la I Guerra Mundial y, por extensión, el radical cambio que sufrió su vida al tener que trasladarse a España desde su Francia natal por culpa de los problemas que los orígenes germanos de su padre hubieran podido suponer en el tenso ambiente que se vivía en el país galo:

Había un problema que me preocupaba mucho cuando pasé la frontera. Pensé: al fin voy a saber la verdad. Voy a un país neutro, así que podré saber lo que pasa en Alemania, lo que pasa en Francia. Voy a saber la verdad. Y, aunque los franceses y los alemanes tenían toda la libertad para hacer llegar sus noticias, nunca me enteré de nada.

Para Aub, resulta imposible acceder a la verdad única y, en consecuencia, a lo único que se puede aspirar es a la consecución de una "verdad múltiple", la que mejor se amolda al carácter heterogéneo, variado y multiforme de la realidad. No en vano, el autor llegó a afirmar que la "realidad es una cosa irreconstruible [que] hay que fabricar" (FMA, Caja 13, 19, 11). De ahí que sus obras no traten tanto de describir el mundo, sino de escribirlo, dejando que "se produzca a sí mismo a través de una escritura capaz de aunar el objetivismo y la mirada solidaria, la distancia crítica y la proyección del propio yo" (Pérez Bowie, 2003: 47). Para ello, prescinde de los puntos de vista unitarios y adopta una mirada tan pluriforme como la propia realidad a la que se refiere, con lo que sus textos quedan caracterizados por la polifonía de voces, por la heterogeneidad de los registros empleados, por la presencia de componentes metaficcionales o por la variedad textual.

Las dificultades que observaba en el proceso reconstructor de la realidad no son óbice para que la crítica haya tendido a analizar buena parte de sus composiciones posteriores a 1939 como "un monumental testimonio de (...) la guerra civil, de sus

14 La analogía con Jusep Torres Campalans es de nuevo evidente. En el prólogo de la ficticia biografía declaraba Max Aub (1992: 15) que iba a intentar hacer "descomposición, apariencia del biografiado desde distintos puntos de vista, sin buscarlo, a la manera de un cuadro cubista". 
prolegómenos y secuelas" (Soldevila, 1999: 105) y un vasto proyecto memorialístico destinado a rememorar sus experiencias y la evolución de España en el siglo XX:

Toda su producción en el exilio mexicano puede ser considerada como el gran intento de crear la imagen de un Occidente revisitado, un "mundo de ayer" -para expresarlo con palabras del exiliado Stephan Zweig- que, no obstante, para el creador de El laberinto mágico jamás cayó en el pasado y menos en el olvido (Ette, 2003: 24).

De hecho, el propio escritor llegó a calificar como "testimonios" a muchos de sus títulos:

No hay escritor de nuestro tiempo que no refleje -más tarde o más temprano, de una manera u otra- las inquietudes de su tiempo. (...) Mis Campos (...) no son novelas, sino crónicas (...). Y en eso San Juan, No, De algún tiempo a esta parte, el Diario de Djelfa y tantas otras cosas más no son, no quieren ser otra cosa que un testimonio (Aub, 1998: 136).

Siempre se mostró muy crítico con las novelas escritas sobre la guerra española que no se ceñían a la verdad de lo sucedido. De Los cipreses creen en Dios afirmó que era "totalmente falso lo que cuenta, no sólo el ambiente: falso todo", mientras que de Las últimas banderas dijo que presentaba una "visión idílica" (FMA, Caja 13, 19, 5). Y es que para Aub, la ficción podía -y debía- ser un medio a través del que reflejar la realidad ${ }^{15}$, con lo que en sus palabras parece atisbarse la existencia de una interpretación de lo leído análoga a la que autores de las últimas corrientes de Teoría de la Literatura han dado el nombre de "ambigua" (Alberca, 2007) o "cuasipragmática" (Stierle, 1987) ${ }^{16}$. En la novela, por tanto, puede haber lugar para la verdad:

Las novelas son testimonios. Las crónicas que hubo durante toda la Edad Media y en el tiempo de los Reyes Católicos hasta el XVI, en el tiempo en que se establecen todas las crónicas -me refiero a las crónicas oficiales- [se basaban en que] el rey o el príncipe pagaba a un señor para que escribiera los hechos de su reinado. Aquí [los escritores] lo hacemos gratis e intentamos [dar] un reflejo de la realidad, porque no hay duda alguna de que el novelista está tan cerca de la historia y la verdad histórica, si es una persona decente, como es de suponer, como todo historiador (FMA, Caja 13, 19, 26).

La interpretación de la obra como testimonio obliga a revisar las relaciones existentes entre su creación artística y su propia experiencia. Según los estudiosos

15 En la citada entrevista de 1968 (FMA, Caja 13, 19, 25), tremendamente útil para profundizar en sus concepciones estéticas, cita como ejemplos que confirmen su afirmación las obras de Stendhal, Benito Pérez Galdós, Lev Tolstoi, Pío Baroja y Roger Martin du Gard, interpretadas como precedentes del realismo por él propugnado, afirmando que en una obra del último de los novelistas citados -Jean Barois- se hallan las más claras influencias de su forma de reconstruir la historia y la propia peripecia vital a través de la novela.

$16 \mathrm{El}$ "pacto ambiguo" ha sido definido como un modelo de lectura que se sitúa a medio camino la referencialidad y la ficción. Según Alberca (2007: 61-62), a través de semejante contrato lector se produciría una recepción "que mantiene una relación con respecto a lo real y a lo vivido, pero [que] los autores, al proponer el estatuto de ficción, le confieren un carácter textual". Mientras, "la lectura causipragmática" hace referencia a un concepto creado por Karlheinz Stierle (1987: 104) al estudiar cómo los textos de ficción pueden producir una recepción que intenta provocar en el receptor una ilusión de realidad. Esta modalidad lectora se situaría entre las dos tipologías clásicas, la pragmática y la no pragmática o ficcional, diferenciadas por la posibilidad de someterse al criterio de veracidad. A través de la lectura cuasipragmática, un texto de ficción puede ser interpretado como si fuera real, pero teniendo siempre en cuenta que, por su carácter literario, es autorreferencial y, por tanto, todo lo que en él se cuente, aunque parta de una experiencia real, existe sólo porque aparece en el papel. 
encargados de investigar la vida del autor, durante la Guerra Civil, el momento en el que con más fuerza se convenció de la necesidad de hacer de su literatura un testimonio ético de la sociedad de su tiempo, Aub comenzó a tomar notas de todo lo que veía a su alrededor, a documentarse sobre aquellos sucesos que no pudo presenciar y a cotejar con diversas personas sus opiniones y visiones del conflicto (Soldevila, 1999: 41-42 y Tuñón de Lara, 1970: 15-17). Durante su estancia en los campos de concentración de Vernet y, sobre todo, Djelfa, esta labor memorialista fue especialmente intensa. Sin embargo, y teniendo en cuenta las limitaciones que percibía en las formas tradicionales de narrar dependientes de un único punto de vista, la narrativa de Aub nunca se basó únicamente en sus propias vivencias, como él mismo reconoció:

Los recuerdos se olvidan, que el hombre dura menos que la memoria (...). No me sirvió nunca la memoria con fidelidad, he recurrido constantemente a la de otros. (...) Nadie ve todo igual, es decir todos ciegos, y sin contar que no somos cíclopes y dos, cuatro, seis ojos ven más que uno, pero siempre desde ángulos distintos. La novela no es sino reducir a memoria lo olvidado o imaginado que viene a ser, para los demás, lo mismo pero siempre desde ángulos distintos (FMA, Caja 22, 1).

Para Aub, la mejor forma de escribir sobre su propia vida era transformando sus experiencias a través del artificio, como enfatizó al afirmar que sus "novelas de la guerra de España (...) se acercan bastante a la verdad, porque (...) no son autobiográficas en ningún momento, porque (...) todo lo autobiográfico sí se presta muy fácilmente a faltar a la verdad" (FMA, Caja 19, 13, 28). Llegó a decir el autor que con el relato de las vivencias personales no se reflejaba la realidad, por lo que "es mejor hablar con todo el mundo para apegarse a la historia" (FMA, Caja 13, 19, 7). La desconfianza en su propia percepción para aprehender la realidad y la necesidad de mirar ésta desde diversos puntos de vista están en la base de su poética. No en vano, la desconfianza en su propio discurso está siempre presente, y como reacción a ella han de entenderse sus continuas reflexiones metaficcionales, sus intentos de mostrar los mismos elementos desde diversos puntos de vista o la duda permanente que parece instalarse en sus obras.

En general, las novelas y los relatos a través de los que efectúa la reconstrucción y la reinterpretación de los acontecimientos que marcaron la evolución del país durante los primeros cuarenta años del siglo XX pueden ser considerados como "narraciones ambientales" que, lejos de focalizar la acción en un personaje concreto, se convierten en mosaicos que, gracias a lo que José Antonio Pérez Bowie (1997: 85) ha denominado "visión caleidoscópica"17, permiten ofrecer una crónica de un periodo concreto. Salvo contadas excepciones, el primer plano no está ocupado por héroes singulares, sino por un complejo y heterogéneo entramado de personajes cuyas peripecias se van entrecruzando de forma progresiva para terminar generando una visión global y polifónica. La calle de Valverde, Campo abierto, Campo de sangre, Campo del Moro y Campo

17 Juego de cartas, publicado en 1964, es quizá el título en la que de forma más clara se muestra esa visión fragmentaria de la realidad. Es una curiosa y original obra compuesta de 108 epístolas a través de las que se va configurando, en un claro ejercicio de multiperspectivismo posmoderno, la personalidad del difunto personaje Máximo Ballesteros -cuyo nombre recuerda, en uno más de los juegos destinados a difuminar los límites entre realidad y ficción, al del autor-. 
de almendros, y también muchos de los relatos aubianos, presentan esta estructura. El multiperspectivismo entronca con la siempre presente voluntad extrañante de la literatura del autor, así como con sus continuos desafíos a la permeabilidad de los límites entre la realidad y la ficción. Todo ello termina por dotar a su estética de un carácter que va más allá de la mera descripción superficial e intenta penetrar hasta el fondo de las cosas, pues, no en vano, "el arte es suma incomprensión del mundo incomprensible" (Aub, 2003: 91). De esta forma, su realismo termina por convertirse en "realismo trascendente" (Pérez Bowie, 2006: 493 y Rodríguez, 1996). Partiendo de semejantes bases, y fijándose fundamentalmente en el hecho de que la fabulación puede ser un medio válido para comprender y hacer comprender la realidad social e histórica, Caudet (1994: 13) ha optado por referirse a la estética aubiana como "realismo histórico". Sebastián Faber (2002) ha empleado el sintagma "realismo apórico", aludiendo con él a cómo la obra de Aub no expresa sino la imposibilidad de reflejar la realidad, tanto por el ya mencionado carácter inaprensible como por el hecho de que, como exiliado, vive fuera del tiempo, del espacio y de la historia, con lo que queda incapacitado para referirse a ella. Manuel Aznar (2003: 313), por su parte, ha explicado cómo la técnica empleada por el autor, a la que denomina "realismo testimonial", hace inútil la tentación de intentar identificar exclusivamente lo narrado en las obras con las vivencias del autor:

El realismo testimonial de Max Aub no implica en absoluto el autobiografismo. Por el contrario, su técnica narrativa se funda en la polifonía y el dialogismo, tan característicos de toda su obra literaria. (...) Realismo testimonial maxaubiano que, como toda creación literaria, es por tanto mentira artística, aunque, eso sí, mentira de verdades históricas.

Siguiendo las indicaciones del propio autor, habitualmente se ha identificado esa labor testimonial con las obras que integran la serie de El laberinto mágico que, según sus propias palabras, estaba formada por seis novelas -Campo cerrado, Campo abierto, Campo del Moro, Campo de sangre, Campo de los almendros y Campo francés- y alrededor de veinticinco cuentos. No obstante, tal y como ha mostrado Francisco Caudet (2000: 28), resulta inútil limitar el alcance testimonial de su producción, pues la función reconstructora de la historia está presente también en La calle de Valverde, Las buenas intenciones, Jusep Torres Campalans, en el discurso de ingreso en la Academia de la Lengua, e incluso en obras de teatro como San Juan, El rapto de Europa o Morir por cerrar los ojos, en poemarios como Diario de Djelfa o en los ensayos recogidos en Hablo como hombre.

Los acontecimientos históricos y la propia experiencia de Aub están en la base de la creación de esos frescos, pero en ningún caso puede otorgarse a estas obras el calificativo de históricas o autobiográficas, pues en ellas hay cabida también para los contenidos ficcionales. Remitirían, pues, a un doble espacio referencial, formado, respectivamente, por un mundo verificable y por otro surgido exclusivamente de la imaginación de Aub, pero compuesto y presentado de forma que los lectores puedan interpretarlo como real o, al menos, como verosímil. El equilibrio entre el valor testimonial e histórico de las obras y la capacidad inventiva de su autor ha sido explicado del siguiente modo por Ignacio Soldevila (1973: 256): 
Aub ha cuidado siempre de reproducir, con fidelidad a sus fuentes de información, la parte -gran parte- de historia contemporánea que hay en su obra narrativa. Lo que no quiere decir que la fantasía del escritor no haga lo que le toca, con espejos multiplicados o deformadores. Pero cada vez que un acontecimiento de la historia pasa por las páginas de su narrativa, cada vez que los hombres con nombre en la Historia circulan por ellas, el creador se constriñe a la labor concisa de documentalista.

Paradójicamente, el valor testimonial de las obras de Aub no queda diluido por la presencia de materiales ficcionales. Las anónimas historias de los cientos de personajes que se asoman por sus páginas hacen cobrar a éstas su verdadera dimensión épica. Esta característica es especialmente perceptible en las novelas ambientadas en la Guerra Civil, en las que las diversas peripecias de los protagonistas son las que muestran con mayor dramatismo el sufrimiento y el dolor inherentes al conflicto. Su presencia constituye, además de un acto de agradecimiento y homenaje a toda la masa ciudadana anónima excluida del proyecto político e ideológico con el que a partir de 1939 se identificó España, una de las únicas formas a través de las que Aub pudo luchar contra la interpretación oficialista de la historia que se hacía desde el poder. Presentar las vidas -reales o susceptibles de haberlo sido- era una forma de contrarrestar a los listados de "caídos por Dios y por España" que poblaron el país desde el final de la Guerra Civil.

Por tanto, el modelo de lectura que parece imponerse ante las obras a través de las que evoca su pasado español, reconstruye su experiencia en los campos de concentración o narra el presente del colectivo exiliado en México es el cuasipragmático. Aunque incluyen acontecimientos y personajes cuya existencia es susceptible de ser verificada, también dan cabida a elementos propios del mundo ficcional. Su obra es, por tanto, una reconstrucción histórica hecha a base de mentiras que, teniendo en cuenta que no se corresponde puntualmente con la realidad de lo ocurrido, puede interpretarse como una verdad esencial -“discurso con pretensiones de verdad relativizada", lo llamó Soldevila (1996: 52)- que, al tener su origen en experiencias autobiográficas o generacionales, se sitúa en el ámbito del espacio autobiográfico y, por tanto, del pacto ambiguo. Como víctima y superviviente, tenía la obligación moral de contar lo vivido y, consciente de que la ausencia de exactitud no tenía por qué implicar una falsificación de la realidad y de que también en la ficción podía latir la verdad, antepuso a su autoimposición testimonial la voluntad estética.

\section{BIBLIOGRAFÍA}

Albaladejo, T. (1986): Teoría de los mundos posibles y macroestructura narrativa, Alicante, Universidad de Alicante.

Alberca, N. (2007): El pacto ambiguo, Madrid, Biblioteca Nueva.

Alonso, C. (ed.) (1996): Actas del Congreso Internacional "Max Aub y El laberinto español", Valencia, Ajuntament de Valencia.

Aub, M. (1970): Novelas escogidas, México D. F., Aguilar. 
Aub, M. (1985): Conversaciones con Buñuel. Seguidas de 45 entrevistas con familiares, amigos y colaboradores del cineasta aragonés. Madrid: Aguilar.

Aub, M. (1992): Jusep Torres Campalans, La Habana. Arte y Literatura.

Aub, M. (1997): La calle de Valverde, Madrid, Cátedra.

Aub, M. (1998): Diarios (1939-1972), Barcelona, Alba.

Aub, M. (2000): Campo de los almendros, Madrid, Castalia.

Aub, M. (2002): Hablo como hombre, Segorbe: Fundación Max Aub.

Aub, M. (2003): La gallina ciega, Barcelona, Alba.

Aznar Soler, M. (2003): Los laberintos del exilio. Diecisiete estudios sobre la obra literaria de Max Aub, Sevilla, Renacimiento.

Bonet, J. M. (2004): “Max Aub, editor y tipógrafo”, en G. Santonja (ed.) (2004): 131133.

Caudet, F. (1994): “El realismo histórico de Max Aub”, Ínsula, 569: 13-15.

_ (2000). "Introducción biográfica y crítica", en M. Aub (2000): 7-112.

Cuesta, J. (2008): La odisea de la memoria, Madrid, Alianza.

Ette, O. (2003): "El Occidente revisitado. Max Aub: escribir (desde) el movimiento", Revista de Occidente, 265, 9-24.

Faber, S. (1998): “Max Aub o la aporía del exilio", Laberintos: revista de estudios sobre los exilios españoles, 1: 5-23.

Faber, S. (2003): "Escribir a chorro suelto: el miedo a borrar y otras obsesiones exílicas", Ínsula, 678: 11-14.

Malgat, G. (2007): Max Aub y Francia o la esperanza traicionada, Segorbe - Sevilla: Fundación Max Aub - Renacimiento.

Mas I Uso, P. (2006): “Lo real de la ficción: de Max Aub a Antonio Muñoz Molina”, El correo de Euclides, 1, 75-79.

Mayoral, J. A. (1987): Estética de la recepción, Madrid, Arco/Libros.

Meyer, E. (2007): Los tiempos mexicanos de Max Aub. Legado periodístico (1943-1972), Madrid, Fondo de Cultura Económica.

Pérez Bazo, J. (1996): “Max Aub en la Real Academia Española: discurso apócrifo del discurso que nunca fue", en C. Alonso (ed.) (1996): 349-365.

Pérez Bowie, J. A. (1997): “Introducción”, en M. Aub (1997): 13-114.

Pérez Bowie, J. A. (2006): “En torno a la concepción aubiana del realismo”. El correo de Euclides, 1: 486-495.

Oleza, J. (2005): “Max Aub entre Petreña y Buñuel: estrategias del antagonismo”, en J. Valender y G. Rojo (eds.) (2005): 15-37.

Ricoeur, P. (2004): La memoria, la historia, el olvido, México D. F., Fondo de Cultura Económica.

Rodríguez, J. (1996): “El realismo trascendente de Las buenas intenciones”, en C. Alonso (ed.) (1996): 533-543. 
Santonja, G. (ed.) (2004): Aproximación a Max Aub, Madrid, Sociedad Estatal de Conmemoraciones Culturales.

Soldevila Durante, I. (1973): La obra narrativa de Max Aub (1929-1969), Madrid,Gredos.

Soldevila Durante, I. (1999): El compromiso de la imaginación. Vida y obra de Max Aub, Segorbe, Fundación Max Aub.

Stierle, K. (1987). “Qué significa 'recepción’ en los textos de ficción?”, en J. A. Mayoral (ed.) (1987): 87-144.

Tuñón de Lara, M. (1970): “Prólogo", en M. Aub (1970): 9-69.

Ugarte, M. (1999). Literatura española del exilio. Un estudio comparativo. Madrid: Siglo XXI.

Valender J. y Rojo G. (eds.) (2005): Homenaje a Max Aub, México D. F., El Colegio de México. 